\title{
PERCEPÇÃO SUBJETIVA DE MEMÓRIA, IDENTIDADE SOCIAL E ENVELHECIMENTO
}

\section{SUBJECTIVE PERCEPTION OF MEMORY, SOCIAL IDENTITY AND AGING}

\author{
Zayanna Christine Lopes Lindôso \\ Curso de Graduação em Terapia Ocupacional, Universidade Federal de Pelotas (UFPel), Av. Duque de Caxias, \\ 250, 96030-001, Pelotas, Brasil. Email: zayanna@gmail.com
}

\begin{abstract}
Resumo: Neste artigo se encontram os resultados de um estudo realizado com quatro idosos inseridos numa universidade sênior da cidade de Lisboa (Portugal). O objetivo foi verificar se existe relação entre a percepção subjetiva de memória, a identidade social e o envelhecimento. Trata-se de um estudo transversal, descritivo e qualitativo com análise das informações recolhidas por meio da narrativa de vida do idoso. Quatro idosos de ambos os sexos, com idade igual ou superior a 65 anos participaram do estudo. A percepção sobre o envelhecimento foi considerada predominantemente negativa com poucos destaques positivos, as queixas de memória estiveram presentes em todos os relatos e os laços sociais têm sido mantidos pelos idosos. Os resultados levaram a conclusão de que existe relação entre percepção subjetiva de memória, identidade social e envelhecimento e apontaram a necessidade de mais estudos.
\end{abstract}

Palavras-chave: percepção subjetiva de memória, identidade social, envelhecimento, idoso.

\begin{abstract}
In this article it is shown the results of a study done with four elderly attending a senior university in Lisbon (Portugal). The aim was to verify if there is a relation among the subjective perception of memory, social identity and aging. It is a transversal, descriptive and qualitative study with information analysis carried out through the elderly's life narration. Four elderly of both sexes, aged 65 or more, took part in the study. The perception about aging was considered predominantly negative showing few positive highlights, the memory complaints were present in all stories and the social ties have been kept by elderly. These results show a relation between the subjective perception of memory, social identity and aging and highlight the importance of additional studies.
\end{abstract}

Keywords: subjective perception of memory, social identity, aging, elderly.

\section{Introdução}

O presente estudo pretende expor uma temática atual e muito presente na vida dos idosos, a memória. Entretanto, ela não surge aqui de forma isolada e numa linguagem exclusivamente clínica. Ela se alia ao envelhecimento e à identidade social. Cada vez mais torna-se importante atentarmos para a memória de maneira multidimensional, mesmo porque o próprio processo de envelhecimento também se dá dentro desta mesma multidimensionalidade e partindo de uma visão holística não se pode separar sujeito e o meio em que se encontra, pois ambos necessitam um do outro para que haja a construção de uma história de vida. 
Ao longo da vida construímos e vivemos nossas vidas dentro de uma sociedade que nos demanda constantemente uma série de posicionamentos e comportamentos que para serem possíveis necessitam processar diversos tipos de informações em diferentes momentos. Cada situação tem suas exigências específicas e causam reflexos nas nossas percepções, emoções, atitudes, decisões e contribuem para a formação de nossas memórias que têm na elaboração da lembrança uma maneira de acessar futuramente o conteúdo dessas situações vividas. Adicionalmente, há ainda o reflexo causado na construção e manutenção da nossa identidade dentro da sociedade.

Partindo da premissa de que a memória é multidimensional, o presente estudo busca verificar se existe relação entre a percepção subjetiva de memória, a identidade social e o envelhecimento. $\mathrm{O}$ foco principal do estudo está na relação feita entre a fala do idoso e estes três aspectos centrais. Primeiramente será necessário fundamentar teoricamente cada um desses aspectos para que posteriormente seja possível descrever os pontos em comum. Para isso se propôs aqui a realizar um estudo transversal, descritivo e qualitativo com análise das informações de acordo com as narrativas de vida dos idosos obtidas por meio de diálogos gravados com o devido consentimento dos participantes.

O estudo apresenta na análise das informações a indicação das semelhanças e diferenças entre os resultados encontrados com as teorias relacionadas ao envelhecimento e à vida social. Nesse sentido, foram utilizadas as teorias sociais do envelhecimento e a teoria das representações sociais.

Acreditamos que apesar de já haver na teoria informações pertinentes sobre a memória, o envelhecimento e os aspectos sociais, ainda há uma necessidade importante de chamarmos a atenção para esse assunto pois nem sempre os idosos se dão conta da abrangência do funcionamento da memória e de como ela interfere em sua vida social. A forma como o idoso se percebe e percebe sua memória estão entre os fatores determinantes para mantê-lo na vida em sociedade e por esta razão o presente estudo pretende contribuir para promover e/ou manter a qualidade de vida do idoso.

Nos tópicos que seguem inicia-se o sequenciamento do estudo com as fundamentações teóricas necessárias já citadas anteriormente.

\section{Processo de envelhecimento, memória e identidade social}

O processo de envelhecimento é um processo natural da vida. Ele engloba uma série de modificações que ocorrem no organismo e interfere nos aspectos biológicos, sociais e psicológicos (Lima \& Cammarota, 2012). O processo de envelhecimento 
pode apresentar-se de maneira natural ou patológica, onde nesta última a qualidade de vida do idoso pode ficar seriamente comprometida (Lima \& Cammarota, 2012).

As alterações psicológicas e sociais que englobam o envelhecimento referem-se às dificuldades cognitivas (dificuldades de recordar números de telefone, nomes e objetos guardados); diminuição do ritmo de aprendizagem de novas tarefas; dificuldade de adaptação a novos papéis sociais; falta de motivação; baixa autoestima e autoimagem (crise de identidade); dificuldade em se adaptar a mudanças rápidas; perdas orgânicas e afetivas; suicídios; somatizações; paranoia; hipocondria; depressão; aposentadoria (reforma); perda da autonomia, da independência e do poder de decisão; e diminuição dos contatos sociais (Fechine \& Trompieri, 2012).

Essas alterações interferem diretamente no modo de vida escolhido pelo indivíduo e influencia as representações sociais que a velhice pode proporcionar ao mesmo. Daniel, Antunes \& Amaral (2015) mencionam que o processo de socialização está diretamente relacionado à identidade coletiva. Poderíamos então dizer que esta relação depende da interação do indivíduo diante dos fatores externos (ambiente) e de como estes o permitirão agir e pensar. Os autores descrevem ainda que "no pensamento de Durkheim (...), a sociedade e a consciência coletiva são entidades morais" (Daniel, Antunes \& Amaral, 2015, p. 291), o que reforça o fato de que os sentimentos, percepções e pensamentos do indivíduo culminarão em comportamentos que muitas vezes serão estabelecidos pela própria sociedade. Porém, tudo dependerá da maneira encontrada pelo indivíduo para vivenciar seu processo de socialização. As transformações sociais (societárias) vividas pelos diferentes grupos e agentes sociais são resultados dessas relações.

As concepções para o que se chama de "Modernidade Reflexiva" vêm a complementar as relações abordadas no parágrafo anterior. Essa modernidade reflexiva representa um momento mais contemporâneo de nossa sociedade que segue vivenciando transformações societárias que trazem apenas consequências sociais. Segundo Beck a "modernização reflexiva significa a possibilidade de uma (auto) destruição criativa de toda uma época: a da sociedade industrial." O autor complementa afirmando que: "o sujeito desta destruição criativa, não é a revolução, nem a crise, mas a vitória da modernização ocidental” (Beck, 2000, p. 2).

Entendendo se tratar de um processo multidimensional, podemos pensar que o processo de modernização permite interpretações diversas diante da vida de um indivíduo. Suas vivências se transformam em memórias e são acessadas sempre que há tal necessidade. Cada um as vivencia à sua maneira e essa individualidade não repercute somente para si mas também para a sociedade. Pensar na 
memória sob esta perspectiva nos permite entender que sempre haverá diferenças e semelhanças na percepção do indivíduo e que a intensidade com que se apresentarão em seu discurso dependerá da forma pela qual os acontecimentos surgem, ou ainda, se pensarmos em pesquisas/estudos qualitativos, da maneira como se apresentam diante de um investigador.

A memória é tida como sendo uma função cognitiva de suma importância na vida de um indivíduo, uma vez que engloba a capacidade de guardar informações. Trata-se da característica adaptativa mais relevante no processo de envelhecimento saudável. Ela se reflete também no bem-estar psicológico e social e permite ao indivíduo o sentimento de pertencimento à sociedade (Lima \& Cammarota, 2012). Diante disto, podemos perceber que a memória é mais do que simplesmente um arquivo onde armazenamos informações e as acessamos quando necessário. Ela é parte integrante da nossa vida e de suma importância para que consigamos manter laços sociais.

O tempo de duração da memória tem sido alvo de muitas queixas entre os idosos que referem esquecimentos relacionados a diminuição da capacidade de reter informações em determinados períodos de tempo. É de conhecimento que o avanço da idade acarreta alterações na memória. Kral (1962) descreveu dois tipos destas alterações nos idosos e destacou o termo "esquecimento" na nomenclatura, que é um termo mencionado sempre de forma secundária em relação a memória. $\mathrm{O}$ primeiro tipo é denominado por "esquecimento senescente benigno" e se refere ao envelhecimento normal. Já o segundo tipo, é denominado por "esquecimento senescente maligno" e estaria diretamente relacionado à demência (Espírito-Santo, Pena, Garcia, Pires, Couto \& Daniel, 2016) 1 .

Do ponto de vista teórico e histórico, diversas contribuições já foram descritas sobre o funcionamento da memória. Os estudos sobre memória datam de 1890 quando um professor de escola chamado Jacobs desenvolveu uma técnica para investigar a memória de crianças. Neste período, a memória era vista de maneira metafórica. A exemplo disto, Platão comparou a memória a um aviário. Para ele os pássaros representavam uma espécie de memória específica onde as informações eram guardadas e acessadas, e ao acessar essas informações, o homem estaria segurando um desses pássaros (Mota, 2000). Tratava-se de um sistema monolítico onde as memórias de um indivíduo eram guardadas e armazenadas num modo classificatório, como se fosse uma grande biblioteca. Essa forma de se perceber a memória perdurou por muito tempo até que novos estudos surgiram.

Contraposições à teoria de Platão foram surgindo e no século XIX a memória passa a percepcionada como sendo organizada por meio de dois sistemas: a "memória primária", que dizia respeito as informações conscientes mantidas na " 
mente" e estavam relacionadas aos aspectos psicológicos do indivíduo, e a "memória secundária" que dizia respeito as informações já transferidas para o inconsciente do indivíduo fazendo parte assim de seu passado psicológico (Mota, 2000).

O estudo de Mota (2000) aponta que a década de 1950 culminou no surgimento de diversos estudos sobre a memória. O autor descreve que Hebb propôs que a memória poderia ser dividida em "memória de curto prazo" e "memória de longo prazo" e que estes dois sistemas ocupariam lugares diferentes de armazenamento e teriam diferentes características neuropsicológicas.

Estudos posteriores trouxeram novas visões que dissociavam esses dois tipos de memória partindo das seguintes premissas: 1- As características destas memórias são diferentes; 2- Estas memórias ocupam lugares diferentes de armazenamento; e 3- Diferentemente da memória de longo prazo, a memória de curto prazo teria uma capacidade limitada (Mota, 2000). Além disso, essas visões se mantinham exclusivamente no campo individual. Já a partir dos estudos de Maurice Halbwachs (1877-1945), parte-se deste campo para uma dimensão que vai além do plano individual ao permitir considerar o aspecto social da memória (Mota, 2000).

De acordo com Cordeiro (2015), Maurice Halbwachs é um nome importante da sociologia francesa da primeira metade do século XX². Além da memória, Halbwachs também abordou temas como classes sociais, demografia, vida urbana, dentre outros. Do ponto de vista histórico, Cordeiro (2015) descreve que a memória ganhou notoriedade nas ciências humanas, nas artes e na literatura no final do século XIX e meados do século XX. Diferentes abordagens foram elaboradas nesta época, especialmente, no campo biológico. Porém, outras visões foram ganhando espaço e apresentaram semelhanças aos pensamentos de Halbwachs, a memória já não se resumiria somente ao domínio biológico.

Halbwachs foi muito influenciado por Émile Durkheim e Henri Bergson, porém assumiu posições que, para alguns autores, foram consideradas uma diferença importante e até além da visão "fechada" de Durkheim em relação à memória. Halbwachs acreditava na interpretação da consciência e era contra a ideia de uma consciência impermeável (Cordeiro, 2015).

A permeabilidade da consciência na qual acreditava Halbwachs indica que a obtenção de uma lembrança não se forma somente por reconstituição das partes mas também com base nos pensamentos do grupo que igualmente compõe uma sociedade e contribuem também na formação de uma memória social (Silva, 2016). Nesse sentido, a memória social surge enquanto ferramenta de estruturação dos sistemas de uma sociedade. Isto significa que as atitudes, pensamentos, regras sociais, reminiscências, ciência, tecnologia e padrões cognitivos são parte dessa estruturação, e só podem ser separadas para fins de análise, ou seja, a interrelação 
existente entre estes aspectos permanece. O próprio imaginário é outro fator a ser considerado (Domingues, 1999). Ao pensarmos na vida em sociedade podemos perceber que tais aspectos são agentes influenciadores também nas relações sociais de um indivíduo, relações estas que são igualmente componentes do processo de estruturação social.

Se o reconhecimento dos aspectos sociais devem ser considerados em relação à memória, e entendendo também que há necessidade de interação entre o indivíduo e o meio na formação de atitudes e pensamentos, convém destacar a importância de o indivíduo idoso saber tecer seus próprios pensamentos acerca de sua memória e de como ela funciona. Um estudo realizado por Lindôso, Cammarota, Argimon, Gomes \& Schwanke (2011) destacou a importância de o idoso saber observar e perceber melhor sua memória para lidar com as atividades de seu cotidiano. Ao verbalizar sobre sua memória o idoso pode compreender melhor suas limitações e potencialidades, e isto se confirma também no estudo de Vieira (2004).

Ainda considerando os estudos anteriormente citados, podemos ampliar a importância da percepção subjetiva do idoso para as questões referentes à sua identidade social tendo em vista sua constante interação com o meio que influencia a construção da sua vida social. As abordagens referentes à identidade desenvolvem-se partindo de conceitos que envolvem duas dimensões: a individual e a colectiva. Ela está vinculada a um sistema social onde o indivíduo se localiza e é localizado socialmente (Berlatto, 2009). A construção da identidade também é simbólica na medida em que "Existe uma associação entre a identidade da pessoa e as coisas que uma pessoa usa" (Woodward, 2000, p. 10). Além disso, a identidade seria também uma necessidade de sobrevivência e de intrínsecas variações das relações sociais que delimitam o contexto do espaço e do tempo em que a pessoa está inserida (Santinello, 2011).

Hall (2003) destaca três concepções de identidade: sujeito do iluminismo, sujeito sociológico e sujeito pós-moderno. A primeira concepção vê o indivíduo de forma unificada, centrada, dotado de razão e consciência de ação. "O centro essencial do eu era a identidade de uma pessoa" (Hall, 2003, p. 11). A segunda concepção percepciona o sujeito como um reflexo da crescente complexidade do mundo moderno, onde a consciência do interior desse sujeito não é considerada autônoma ou autossuficiente. Ela implicaria uma relação que permite o sujeito mediar valores, sentidos e símbolos com um foco na cultura do mundo por ele habitado (Hall, 2003). Já na terceira concepção, o indivíduo é visto como não tendo uma identidade fixa, essencial ou permanente. A identidade é aí apreendida como sendo continuamente transformada de acordo com o sistema cultural que rodeia o sujeito, trazendo assim uma definição histórica e não biológica (Hall, 2003). 
No que se refere ao envelhecimento, percebemos que a identidade de certa forma faz parte desse processo. Os hábitos, crenças e imagens alteram de forma significativa as concepções ligadas às etapas mais tardias da vida. O estudo de Silva (2008) questiona se a idade seria uma nova identidade etária. Ao trazer a classificação das idades (da primeira à quarta idade) a autora inclui a identidade como um fator presente na vida do indivíduo e destaca alguns questionamentos envolvendo a velhice e o termo terceira idade. As duas são observadas como identidades ligadas ao envelhecimento, porém as repercussões destas na vida do idoso se diferenciam devido as consequências que as mesmas proporcionam ao serem diferentemente interpretadas. A terceira idade, nesse âmbito, denota a uma visão mais positiva do envelhecimento ao passo que a velhice é vista como fonte de perdas. Isto também representa um marco para a compreensão social do envelhecimento.

De acordo com essas concepções de identidade é possível observar que existem diferentes formas de estarmos inseridos no meio social. Essas teorias não buscam moldar o homem, mas sim, compreender de que forma ele pode fazer parte e sentir-se parte de uma sociedade. A relação com outras pessoas parece ser um aspecto importante onde juntamente com a cultura na qual estamos inseridos poderão determinar formas de vida e de desenvolvimento de laços sociais, e isso pode favorecer ao homem o sentimento de pertencimento social e de protagonismo, o que nos remete diretamente às práticas sociais.

Bourdieu (2002) apresenta o que ele chama de habitus para explicar a prática social. Trata-se de uma complexa teoria que engloba diversos elementos reflexivos. Um dos destaques diz respeito ao fato da "lógica da prática" ou "domínio prático" não serem confundidos com interação social, com consciência prática, racionalização discursiva ou regras (Caria, 2003). Para Caria (2003, p. 34) este termo envolve "um conjunto de sistemas pré-reflexivos (disposições), de percepção, apreciação e antecipação que foram produzidos no agente social". Percebemos que o fato do agir e o agir conforme os outros agem são componentes desta teoria que permite ao sujeito momentos de interiorização (por meio dos sistemas sociais) e exteriorização (prática baseada naquilo que foi interiorizado). Caria (2003) destaca, nesse sentido, a importância do improviso social tendo em vista possíveis defasagens entre esses dois processos. Entendemos, portanto, que tal improviso virá da repercusão e da própria história de vida do indivíduo. Caria (2003, p. 35) ainda apresenta que "a diferenciação entre o social e o individual, tantas vezes valorizada pelas ciências sociais, perde sentido porque o indivíduo será sempre o produto estrutural da sua história social face ao estado conjuntural presente das relações de poder". 


\section{Teorias sociais do envelhecimento}

As teorias sociais do envelhecimento surgiram com a finalidade de tentar explicar o processo de envelhecimento e o impacto social desse novo perfil populacional. A teoria do desengajamento diz-nos que o envelhecimento é um processo no qual a sociedade e o indivíduo se retiram ou se desengajam, gradualmente, um do outro para satisfação e benefício mútuo (Doll, Gomes, Hollerweger, Pecoits \& Almeida, 2007; Eliopoulos, 2001; Stamato, 2007). Neri (2013) complementa que o desengajamento é produto da socialização, sem entrar no mérito do crescimento do idoso, eé um requisito funcional para a estabilidade social. Por outro lado, a teoria da continuidade do envelhecimento relaciona as características peculiares do indivíduo ao longo do envelhecimento à aquelas apresentadas na velhice (Eliopoulos, 2001; Stamato, 2007). Já a teoria da subcultura entende os idosos como um grupo com características exclusivas e os separam de outras faixas etárias (Eliopoulos, 2001; Stamato, 2007). A teoria da gerotranscendência indica que à medida que as pessoas envelhecem ficam menos preocupadas com bens materiais, os relacionamentos pouco significativos e os próprios interesses (Eliopoulos, 2001; Stamato, 2007). Por fim, a teoria da atividade defende que as tarefas surgem na vida do indivíduo em períodos determinados, e se forem realizadas com êxito o indivíduo se sentirá feliz, caso fracasse lhe restarão a infelicidade e a reprovação da sociedade na qual pertence (Eliopoulos, 2001; Stamato, 2007).

\section{Teoria das representações sociais}

A teoria das representações sociais foi proposta inicialmente por Serge Moscovici em 1961, e se tem mostrado uma teoria importante por se adequar facilmente à complexidade dos fenômenos sociais presentes na atualidade. De acordo com esta teoria, existe uma articulação entre os aspectos psicológicos e sociais, e isso permite afirmar que não se pode separar a pessoa, objeto e sociedade (Prado \& Sayd, 2006). Para Moscovici o indivíduo não é um ser que processa somente informações (o que implicaria somente em processamento cognitivo), ele é um ser que pensa ativamente e constroe representações e soluções para tudo aquilo que se torna um questionamento para si mesmo (Patriota, 2007).

Estudos que utilizam essa teoria buscam geralmente trocas simbólicas que acontecem nos ambientes sociais e nas relações interpessoais. Do ponto de vista metodológico, esses estudos devem ainda tornar em algo familiar aquilo que era até então desconhecido. Para isso é necessário que se faça categorizações, classificações, nomeação de ideias e acontecimentos inéditos que antes não haviam sido 
encontrados. O estudo deve buscar, portanto, novos significados sociais para o objeto que está sendo estudado (Moraes, Souza, Pinto, Estevam \& Munhoz, 2014).

\section{Materiais e métodos}

O presente estudo é transversal, descritivo e qualitativo, com análise das informações realizada por meio da narrativa de vida do idoso. Trata-se de uma metodologia conforme descrita na obra de Viegas e Gomes (2007), e nesse sentido, a narrativa de vida foi utlizada como meio de produção central da análise da relação entre memória, identidade social e envelhecimento. Além disso, a história de vida opera num contexto de comunicação entre os dois interlocutores: o autor do relato (o idoso) e o autor da história de vida (o investigador).

Os diálogos tiveram duração média de 60 minutos e foram realizados uma única vez. Todos foram gravados e transcritos para que se pudesse manter fielmente as falas trazidas pelos idosos. A população do estudo foi de alunos/idosos ou membros de uma universidade sênior localizada em Lisboa (Portugal). A amostra se deu por conveniência. Para melhor direcionamento do diálogo foi elaborado um formulário de entrevista dividido em seis partes que diziam respeito aos seguintes aspectos: Perfil do Idoso; Percepção sobre o Envelhecimento; Idoso e Identidade; Idoso e Memória; e Estratégias de Recordação. O conteúdo referente a cada item se encontra descrito nos resultados do estudo.

Os critérios para que os idosos fossem incluídos no estudo foram o de terem idade igual ou superior a 65 anos, serem alunos ou membros administrativos da universidade sênior e ter condições de desenvolver o diálogo junto ao autor da história de vida. A escolha por idosos alunos/membros da universidade sênior se justifica pelo fato de se tratar de um espaço que abrange a população de interesse do estudo, ou seja, idosos ativos.

Os procedimentos de pesquisa seguiram o seguinte roteiro: as universidades sêniors foram contatadas por correio eletrônico e telefone para apresentação do estudo e solicitação de autorização do mesmo. Em todos os contatos o investigador responsável apontou a necessidade de uma reunião presencial para fins de esclarecimentos sobre o estudo. Após o retorno da universidade, a reunião seria realizada entre o Diretor da mesma e o investigador e somente depois da autorização da instituição os idosos seriam contatados. Além disso, esse contato deu-se nas dependências da própria universidade em horário combinado junto à diretoria da mesma.

Apenas seis universidades sêniors retornaram o contato feito pelo investigador e somente uma universidade aceitou conhecer o estudo que foi apresentado 
pelo investigador responsável em reunião realizada nas dependências da universidade. O foco da análise dos resultados obtidos foi a percepção do idoso aliado ao envelhecimento e à identidade. Para esta finalidade foram utilizadas as teorias sociais do envelhecimento e a teoria das representações sociais por se tratar de teorias que abrangem os conhecimentos pertinentes à gerontologia e ao contexto social, $\mathrm{e}$ se enquadrarem na proposta do estudo.

As teorias sociais do envelhecimento são de fundamental importância no entendimento do processo de afastamento e/ou proximidade do idoso no ambiente social e sua classificação direciona-se para este fim, permitindo entender de que forma o idoso se posiciona socialmente (tornando-se um dos aspectos primordiais para um envelhecimento bem sucedido). Já a teoria das representações sociais determina a relação entre os aspectos psicológicos (psicologia do conhecimento aqui se inserem as percepções subjetivas do indivíduo) e os sociais. Ela permite a compreensão da realidade social de um indivíduo.

As questões éticas foram respeitadas mantendo em absoluto sigilo a identidade dos idosos e da instituição.

\section{Resultados}

Das seis universidades sêniors que retornaram o contato feito pelo investigador responsável, cinco justificaram o fato de não aceitarem conhecer o estudo. Estas justificativas estavam, em sua maioria, relacionadas ao final do ano letivo. Apenas uma universidade aceitou conhecer o estudo. Os idosos foram contatados em data e horários agendados pelo Diretor da universidade. O investigador responsável reuniu a todos após o término da aula e explicou sobre o estudo. Cerca de 20 alunos estavam presentes neste dia.

Quatro idosos aceitaram participar do estudo. Destes, três eram do sexo feminino e um do sexo masculino. Todos tinham idade a partir de 65 anos até a faixa etária de 80 anos. Um dos participantes não especificou sua idade referindo somente ter mais de 80 anos. Três seguem a religião católica e um revelou ser ateu. Todos, exceto um participante, tiveram filhos e netos e todos reformaram-se. Quanto ao nível de escolaridade, dois participantes estudaram até o quinto ano (atualmente equivale ao nono), um participante tinha nível superior na área de economia e outro tinha formação técnica na área de enfermagem. A seguir se encontram mais algumas informações breves sobre a vida dos idosos para melhor compreensão de suas trajetórias de vida e, ainda, na tentativa de romper o destaque muitas vezes dado aos aspectos biológicos da memória que não representam o único domínio a ser considerado quando se trata deste assunto. 
Sobre o Autor do Relato 1 (71 anos, sexo feminino): católica, nasceu no Norte de Portugal e aos 25 anos de idade foi morar em Lisboa. Estudou até o antigo quinto ano do Liceu, escolheu o curso de Serviço Social que precisou deixar no terceiro ano por alegar sentir-se limitada devido a problemas que teve numa congregação religiosa que foram posteriormente resolvidos. Reformou-se, tem 10 irmãos, todos casados, mantém pouco contato com a família e destacou ter mais contato com o irmão que se encontrava doente e com uma sobrinha. Atua como utente voluntária numa instituição de idosos onde lhes ensina sobre religião. Não casou-se, não teve filhos e revelou nunca ter se sentido voltada para isso e que gosta de sentir-se livre.

Sobre o Autor do Relato 2 (sexo masculino, mais de 80 anos): ateu, nascido em Lisboa. Tem um irmão mais velho. Estudou na escola dominical para ser pastor, porém, desistiu antes de completar dois anos e referiu ter tido muitas dúvidas em relação à religião. Casou-se pela primeira vez ainda muito jovem e teve um filho. Estudou música e depois economia e muitas questões políticas começaram a permear seus pensamentos. Aos 16/17 anos já era militante político. Aos 25 anos foi "detido pela polícia política após a participação eleitoral de 1958" (palavras utilizadas pelo autor). Esteve seis anos preso e por esta razão seu primeiro casamento terminou. Após a fuga da prisão residiu em diversos países e depois de muitos anos retornou a Portugal, onde iniciou novas atividades no âmbito acadêmico: foi professor na Faculdade de Direito de Lisboa como convidado onde conheceu sua atual esposa. Deste segundo casamento não teve filhos, porém, revela considerar a filha de sua esposa como sendo sua filha também. Há 12 anos fundou uma universidade sênior onde diz ter se sentido muito realizado e feliz em poder ajudar outros idosos.

Sobre o Autor do Relato 3 (sexo feminino, 65 anos): nascida na província, vem de uma família pobre que sempre viveu no meio rural. Tem sete irmãos. Revelou ter tido muito amor de seus pais e ter vivido numa família sem grandes conflitos. Sempre foi educada na religião católica, porém, revelou ter deixado de seguir a religião devido ao surgimento de questionamentos que sempre a deixaram com muitas dúvidas (ela não revelou essas dúvidas). É viúva, mora sozinha, tem dois filhos, dois netos e é técnica de enfermagem. Trabalhou por trinta e quatro anos no Hospital Santa Maria e dez anos no Hospital da Cruz Vermelha.

Sobre o Autor do Relato 4 (sexo feminino, 71 anos): nasceu no meio rural, tem 12 irmãos. Desde muito cedo ajudava os pais (que eram agricultores) nas lidas com a terra, no cuidado com os animais e nos cuidados com os irmãos mais novos. Revelou sempre ter tido uma infância tranquila e o amor de seus pais. Sua mãe teve problemas de varizes e por esta razão iam a Lisboa de $15 \mathrm{em} 15$ dias para que ela fizesse o tratamento. Numa dessas idas ela recebeu convite para trabalhar de babá numa casa de família em Lisboa e esse convite foi aceito após a melhora de sua mãe. Depois 
atuou numa multinacional que fabricava televisores, rádios e demais aparelhos eletrônicos. Com a mudança da empresa para outro país ficou desempregada e ainda neste período recebeu diagnóstico de câncer que foi tratado e curado. Depois disso atuou num projeto social que tinha como objetivo tirar as crianças da rua.

O estudo optou por utilizar seus aspectos centrais também como categorias que foram assim organizadas: Percepção sobre Envelhecimento; IdentidadeSocial; e Percepção de Memória/Estratégias de Recordação.

\section{Percepção sobre envelhecimento}

Os idosos relataram suas percepções acerca do envelhecimento por meio de questionamentos relacionados a episódios específicos de sua infância, percepção de quando sentiu que estava entrando na velhice, perdas e aspectos positivos na velhice e se houveram melhoras com a chegada da mesma. Convém relembrar que os idosos são chamados de "Autor do Relato" em conformidade com Viegas e Gomes (2007). Este termo foi utilizado sempre que houve destaque para a fala do idoso.

Todos conseguiram relatar histórias de sua infância, porém tiveram dificuldades de destacar alguma que fosse considerada como sendo mais importante. Somente uma das autoras do relato destacou a lembrança de seu pai falecido quando ela tinha cinco anos de idade. Ela diz:

Lembro-me sempre com carinho do meu pai que faleceu. Eu tinha, acho, uns 5 ou 6 anos e eu sinto muito imenso, faz muita falta (Autor do Relato 1, 71 anos, sexo feminino).

No que se refere as percepções sobre a entrada na velhice o fator tempo foi um destaque nas falas dos idosos onde num dos relatos a idosa referiu sentir-se entrando na velhice aos quarenta anos de idade, passando por outro relato onde a velhice é vista de forma gradual, até a percepção de outro participante que referiu sentir ter entrado na velhice recentemente. Outra fala adotou uma linguagem que se referia aos aspectos diretamente relacionados a velhice tais como os físicos e os psicológicos.

Eu fisicamente acho que percebi isso, mais psicologicamente ou espiritualmente ou não sei como queira chamar eu nunca senti isso (Autor do Relato 1, 71 anos, sexo feminino).

Muito recentemente. Vi que haviam coisas da minha vida que já não recordava com todos os pormenores, e portanto isto se deu como sinal de envelhecimento... (Autor do Relato 2, mais de 80 anos, sexo masculino). 
É, pois. Eu acho que ao longo dos...sei lá, a partir dos 40 anos em função de sentir coisas...pelo menos a partir dos 40 anos que não era habitual sentir e que eu comecei a identificar como realmente preocupações típicas da idade. É, sei lá e uma das coisas que estativamente é...foram até os esquecimentos, por exemplo, esquecer-me sei lá fique isso aí se calhar tinha mesmo já 40 anos talvez. (Autor do Relato 3,65 anos, sexo feminino)

Não! Acho que foi gradualmente (Autor do Relato 4, 65 anos, sexo feminino).

Todos os participantes referiram sentir as diferenças trazidas com a velhice. As visões negativas foram predominantes e focaram-se nas perdas. Somente uma das participantes referiu-se de forma totalmente positiva a esta etapa da vida. Destacamos as falas a seguir:

Não, não, não! Pelo contrário! Eu acho que a velhice nos traz só coisas boas. A experiência do que nós vivemos, tudo que nós vivemos, não sei! A gente viveu muito, nos deu muita sabedoria...(Autor do Relato 1, 71 anos, sexo feminino).

As dores no meu joelho, as dores no corpo, as tendinites que tenho aqui que muitas vezes não se consegue..., o cansaço [...] Portanto, claro em termos físicos é...é uma diferença abismal não é, muito grande em termos de capacidade mesmo... (Autor do Relato 3, 65 anos, sexo feminino)

Também foi possível observar que a percepção da velhice trouxe sentimentos de frustração, humilhação, amor e conformismo que também influenciaram na percepção do envelhecimento por parte dos idosos. Na fala de um de um dos participantes observamos nitidamente o conformismo:

uma coisa que eu tento dizer a mim própria mais muitas vezes não é fácil, é que a gente tem que aceitar, o que não se pode evitar temos que aceitar (Autor do Relato 3, 65 anos, sexo feminino).

Em outro relato o amor surge aliado à sexualidade e como uma limitação que também trouxe suas consequências na vida pessoal. O participante diz:

...também a minha vida privada, a minha vida amorosa também a velhice faz sentir, nas relações sexuais que é um problema pra mim que sempre é...que era a composição integrada do homem, que fazia parte do amor e da concretização do amor que é um dos sentimentos mais profundos que o homem tem. (Autor do Relato 2, mais de 80 anos, sexo masculino) 
A frustração e a humilhação se direcionaram mais a situações de esquecimento que provocaram tais reações nos idosos. As falas que destacamos a seguir têm respectivamente a presença do sentimento de humilhação diante de uma situação em que o participante esqueceu-se de uma peça de roupa que foi enviada para reparos a uma costureira. O de frustração ocorre no momento em que o participante conversa com outras pessoas em que "perde-se" e esquece o que iria comentar. Esta última situação pode ser observada na fala a seguir:

[...] É uma sensação um bocadinho difícil de explicar mais é muito humilhante [...] é uma frustação e então eu sou aquela de ficar calada porque eles querem invadir a conversa e nas alturas já se perdeu os nomes [...] os termos, quero usar adjetivos, termos, não vêm as palavras, não vem, não surgem. (Autor do Relato 3, 65 anos, sexo feminino)

Outras formas negativas sobre a velhice foram trazidas também nas demais categorias descritas a seguir. Convém aqui mencionar que essas categorias não são independentes entre si, elas se interrelacionam para permitir o comportamento humano.

\section{Identidade social}

Neste item os autores do relato falaram sobre a existência ou não de episódios em que se sentiram mal vistos em função da idade; atividades que consideram como lazer; se, com o envelhecimento, deixaram de realizar alguma atividade de lazer; atividades relacionadas ao trabalho, inclusive o trabalho voluntário; atividades do dia-a-dia; crenças próprias; hábitos; a forma como lidam com as tecnologias disponíveis atualmente e se já se sentiram excluídos socialmente por não saber usar alguma dessas tecnologias.

Todos os participantes referiram que nunca se sentiram mal vistos devido a idade com destaque apenas na fala de uma idosa que adicionou que ela mesma se percebe de forma negativa. É possível observar novamente sentimentos de frustração, humilhação e conformismo. Ela diz:

Eu é que muitas vezes me sinto, sinto, que noto essas dificuldades, é...mais... mais... [...] Eu sim, é sim, eu é que me vejo, eu é que me sinto humilhada. Portanto, humilhada, portanto gostaria que fosse diferente. Apesar de tudo, aos 65 anos, eu ainda me cuido. (Autor do Relato 3, 65 anos, sexo feminino)

Nenhum dos idosos deixou de realizar alguma atividade em função da velhice, porém, uma participante revelou um antigo desejo de aprender a falar inglês mais 
que atualmente não se sente mais em condições devido às queixas de memória que possui e o medo de sentir-se frustrada e humilhada. Em seu relato ela diz:

uma coisa que eu posso dizer e que nunca mais tive coragem de retomar é por exemplo inglês, que eu sou fraquinha em inglês e então queria aprender mais e depois que cheguei a história deste esquecimento e hoje agora sei que isto não vou sentir-me muito bem, vou ficar mais frustrada porque não tem nada a ver com quando e...aprendo agora e daqui um bocado já não sei e...isto é uma grande frustação e aqui tava a me deixar mais frustrada pela dificuldade que eu tava de assimilar e eu desisti dessa aula. (Autor do Relato 3, 65 anos, sexo feminino)

Outro ponto observado diz respeito aos reflexos da reforma na vida do idoso. Num dos relatos, este momento da vida surge como um desengajamento social que interferiu também no poder aquisitivo. Por outro lado, eles buscaram na universidade sênior uma forma de sentir-se novamente engajados tendo novos compromissos sem as pressões institucionais de uma rotina de trabalho habitual. Nesse espaço educacional a formação de novos laços sociais permitiu a eles a manutenção e/ou adequação de sua identidade.

Todos os participantes revelaram ter suas crenças que não se encontravam somente relacionadas às questões religiosas, mas, na busca por algo que dê sentido às suas vidas. Uma das participantes cita uma frase de Confúcio relacionando-a a Jesus Cristo como sendo componentes de suas crenças. Ela diz:

Uma crença! Ah eu acredito muito nas palavras de Confúcio: não faças aos outros o que não queres que te façam a ti e faz aos outros aquilo que acha que fazem a ti! Que foi aquilo que foi de Confúcio e depois de Cristo. (Autor do Relato 4, 71 anos, sexo feminino)

No que se refere ao lazer todos revelaram praticar alguma atividade relacionada a este aspecto. Música e leitura foram muito citados, porém a universidade sênior surgiu em todos os relatos como sendo uma opção de lazer.

Quanto ao uso das tecnologias, todos relataram sentir dificuldades, mas apesar disto, as utilizam considerando somente suas necessidades básicas. As tecnologias citadas foram o computador para leitura de $e$-mails, artigos, notícias e assistir vídeos; e o uso do telefone móvel no qual têm preferência por modelos mais simples. Três dos participantes referiram preferir o contato pessoal ao uso das tecnologias para manter-se em contato com as pessoas, foram eles: o Autor do Relato 1, 71 anos, sexo feminino; o Autor do Relato 2, mais de 80 anos, sexo masculino, e o Autor do Relato 4, 65 anos, sexo feminino. 


\section{Percepção de memória/Estratégias de recordação}

Nesta etapa do diálogo os autores dos relatos expressaram sobre a importância da memória, mudanças e perdas ocorridas ao longo dos anos, esquecimentos e tipos informações que mais costumam esquecer. No que se refere às estratégias de recordação os autores revelaram quais soluções encontraram para sanar ou amenizar os esquecimentos, que providências tomaram para manter a memória ativa e se há informações que lembrem com mais mágoa ou com mais alegria.

Todos referiram que a memória é de fato uma função importante para suas vidas. Dois participantes tiveram dificuldades em justificar sobre a importância da memória e focaram diretamente em suas queixas que estavam direcionadas à memória de curta duração (armazenar informações recentes). Referiram ter percebido as alterações ao longo dos anos e que houve diminuição do processamento das informações, principalmente quando estão aprendendo algo novo. Um dos participantes indica que as alterações da memória também estão relacionados às percepções daquilo que vivemos ao longo da vida e que elas são mutáveis, ou seja, um mesmo assunto não será sempre visto da mesma maneira. Em outro relato o idoso refere que não há vida sem memória e destaca que tem uma memória afetiva na qual considera como sendo muito importante.

A memória... Eu penso desta maneira: a minha memória melhorou ou piorou, não, atroz! Isto quer dizer, o que a gente aprende é mutável a todos os momentos. [...] Então o que é que mudou? Muda a sua ideia! Muda a maneira como você percebeu e alterou e registrou a ideia. (Autor do Relato 2, mais de 80 anos, sexo masculino)

É engraçado falar nisso porque se não temos a memória como é que vivemos? Eu não sou especialista (risos). [...] Eu sempre tive, tive muita memória mais eu acho que mais uma memória afetiva é...não sei se existe essa memória.... Pra mim existe! (Autor do Relato 1, 71 anos, sexo feminino)

Os idosos trouxeram uma percepção de memória muito relacionada às suas próprias vivências principalmente quando mencionam as dificuldades em armazenar informações recentes. A percepção de memória dos idosos de uma forma geral obedeceu suas histórias de vida. Suas opiniões nos fazem observar que todos têm consciência de suas dificuldades e tentam lidar com elas, mesmo quando reagem negativamente diante das mesmas. Os relatos não nos permitem apontar que os idosos têm uma percepção positiva ou negativa da memória, mas sim nos permitem perceber que a presença da subjetividade trouxe uma visão mais neutra diante da memória e permitiram ao idoso momentos de reflexão. 
Diante das dificuldades apontadas pelos idosos também foi possível saber o que eles têm feito para manter a memória ativa. Um aspecto em comum, importante a ser destacado, é o fato de todos os autores recorrerem às anotações para evitar o esquecimento. Um dos autores referiu até mesmo guardar as agendas de anos anteriores para que, caso fosse necessário, pudesse acessar alguma informação mais antiga na agenda. Outras atividades relatadas foram memorizar uma palavra-chave para recordar a informação quando necessário, leituras e discussões e a manutenção da rotina.

Os participantes não referiram alguma situação específica em que lembrassem com mais mágoa ou mais alegria. Somente uma participante destacou um acontecimento que lhe marcou positivamente e estava relacionado ao seu trabalho num projeto social ao acompanhar uma criança que era atendida no referido projecto, e que trouxe progressos positivos pelo trabalho desenvolvido na época. Ela relatou o seguinte (informações pessoais e institucionais não foram identificadas por razões éticas):

...uma criança que teve problemas ao nascer, ficou na incubadora, nasceu como morte aparente, depois foi pra incubadora e depois teve muitos problemas mais e....tinha problemas de comunicação e da socialização [...] Nem na escola, nem no colégio eram capaz de lhe fazer falar.[...] Comecei a lidar com ele ao colo da mãe. Já conseguia aproximar-me dele com ele ao colo da mãe, [...] trabalhei com ele por 2 anos. [...] E quando foi para a escola, ah! E a terapeuta perguntou a mãe quando a mãe foi buscar: o que que aconteceu ao J que hoje riu-se pra mim? E a mãe disse: olha ele tá a trabalhar com uma senhora do MJ e tá a fazer um progresso enorme, pronto. Pois..., ah essa senhora que lhe ensina as cores! Ele já as sabe (risos)! Foi muito bom! [...] Ainda hoje me emociono quando penso no J. (Autor do Relato 4, 71 anos, sexo feminino)

Todas as categorias e seus resultados descritos anteriormente trouxeram informações pertinentes para a discussão do presente estudo. Os pontos em comum encontrados nas categorias se referem aos sentimentos de conformismo, frustração, humilhação e amor e o engajamento/desengajamento. Já as diferenças se relacionaram pela forma como cada idoso lida com as situações em que vive e que relataram para o autor da história de vida, permitindo perceber parte do imaginário que cada idoso constrói acerca do próprio envelhecimento. Os pontos em comum anteriromente citados não são vistos como aspectos que uniformizam os idosos, mesmo porque a história de vida é uma experiência individual, mas, de toda forma, semelhanças e diferenças sempre farão parte de seus discursos e se fizeram presente nos resultados aqui encontrados. Na discussão este aspecto será melhor abordado. 


\section{Discussão}

Os resultados do presente estudo nos permite considerar a existência da relação entre a percepção subjetiva de memória, identidade social e o envelhecimento. Para tanto, se fez necessário discutir os aspectos pertinentes desta relação de forma "separada" para facilitar o entendimento, e destacar a importância que cada aspecto tem nesta composição relacional.

Partindo dos pontos em comum (sentimentos de conformismo, frustração, humilhação e amor, e o engajamento/desengajamento) encontrados nas falas dos idosos diante de cada categoria, pudemos perceber que as narrativas de vida nos permitiram observar que de fato existe uma estreita relação entre o que o idoso percebe de sua memória, a identidade social e o processo de envelhecimento.

Viegas e Gomes (2007) afirmam que a produção dos significados centrais dos fatos vividos interfere na análise da identidade de um indivíduo. Sendo assim, nos relatos obtidos foi possível observar que o envelhecimento ainda está focado nas perdas e faz com que o idoso tenha sentimentos de frustração, humilhação e conformismo. Aliás, o conformismo parece ser uma espécie de caminho alternativo mais fácil para lidar com o envelhecimento e ao mesmo tempo ele parece impor ao idoso etapas que permitam uma futura aceitação da velhice.

Sentimentos como amor e humilhação também permeiam no imaginário do idoso. Os sentimentos de humilhação surgidos em decorrência das perdas e/ou falhas comportamentais diante de diferentes situações, permitem ao idoso perceber que suas perdas parecem ser maiores que seus ganhos, e por esta razão sua construção de velhice parece ser um caminho de desafios negativos que precisam ser superados com a continuidade da vida. Percebemos que novamente o conformismo se faz presente. Por outro lado, quando destacam o amor, observa-se que na rotina de cada um existem atividades que lhe dão prazer em executar, e mesmo as limitações físicas citadas não servem como impedimento para realizá-las. Todas estas atividades são exercidas pela escolha do próprio idoso. Pode parecer que há aqui certa contradição, porém, o fato é que as tomadas de decisão dos idosos são os fatores reais para explicar essa característica. O estudo de Deon e Goldim (2016) verificou a capacidade de tomada de decisões do idoso e os resultados mostraram que a maioria dos idosos não institucionalizados se encontrava no quinto nível de desenvolvimento psicológico-moral, o consciencioso. O nível conformista também aparece nos resultados. Esses dois níveis também estiveram presentes nas falas dos idosos deste estudo. Pode-se inclusive adicionar que os idosos também apresentaram características do nível consciencioso.

O desenvolvimento psicológico-moral é a capacidade do ser humano na tomada de decisão e na escolha de tarefas que sejam de seu interesse. Apresenta sete 
níveis: o pré-social (não há condições de compreensão por parte do indivíduo), o impulsivo (indivíduo que age por impulso, sem reflexão prévia), o oportunista (decisões com base no desejo do indivíduo, manipulação), o conformista (decisões baseadas na valorização das crenças do indivíduo), o consciensioso (decisões autonônomas com base nas crenças e desejos mais passível de constrangimento), o autônomo (decisão livre de constrangimento) e o integrado (autonomia e inserção social de forma ampla e complexa) (Deon \& Goldim, 2016).

Diante do exposto, observamos o quanto as decisões e o comportamento que elas geram nos idosos ganham força no sentido de mantê-los ativos ao longo dos anos e lidar com as situações que se apresentam. Pode-se considerar também as interferências dessas decisões na forma que o idoso se sente diante da sociedade, como percebe sua memória e desenvolve/mantém sua identidade. Esse sentimento de pertencimento social, memória, identidade e a própria tomada de decisão por parte dos idosos reflete de forma notória as transformações societárias ocorridas ao longo dos anos coforme já exposto anteriormente. Os idosos de forma geral, vêm buscando adaptar-se às estas transformações desenvolvendo/mantendo também a identidade coletiva necessária para este fim. O estudo de Daniel, Antunes e Amaral (2015) confirma tal informação ao mencionar a relação existente entre a socialização e a identidade coletiva. Portanto, pensamentos, sentimentos e percepções dos idosos terão como resultados comportamentos sociais que poderão ter sido "impostos" pela sociedade ou comportamentos sociais fruto da interação entre a história de vida e o processo de socialização (Daniel, Antunes \& Amaral, 2015).

Outro ponto importante se referiu às atividades de lazer onde foram citados a leitura, música, cinema e teatro. Porém, a universidade sênior surgiu como opção de lazer em todas as falas, trazendo à tona sentimentos de amor, construção de novos laços sociais e como sendo uma das opções para manter-se ativo, pois, a universidade faz parte da rotina dos idosos. A procura por este espaço foi uma tomada de decisão deles próprios.

Em sentido mais amplo a universidade permite a manutenção dos laços sociais e uso das tecnologias atuais. Aliás, no que diz respeito às tecnologias, observa-se que as mesmas são geradoras de insegurança nos idosos e todos as utilizam somente dentro de suas necessidades, ainda assim, nenhum deles referiu sentir-se excluído socialmente em função delas. $\mathrm{O}$ fato é que as tecnologias também são componentes da identidade social (Viegas \& Gomes, 2007).

A percepção que se tem é de que a universidade é um equipamento social que funciona como um fator protetor não somente nas questões cognitivas, como também nos demais aspectos da vida do idoso. O estudo de Inouye, Orlandi, Pavarini \& Pedrazzani (2017) refere que a educação na velhice promove um 
redimensionamento da qualidade de vida com base na interdisciplinaridade, na participação social e na promoção da saúde. O estudo fornece ainda a informação de que a dinamicidade das disciplinas/atividades desenvolvidas nesse espaço deixam claro que não há nada de definitivo nas ofertas visto que as pessoas que procuram este espaço estão também em transformação. Essa transformação citada no estudo remete a pensar nas mudanças ou adequações da identidade social do idoso, que naturalmente busca opções que são de seu interesse e forma nesses locais novos laços sociais e novas formas de lidar com seu próprio envelhecimento.

A universidade também pode se destacar no momento em que os idosos relatam sobre suas crenças, também o lazer e as tecnologias são importantes para a identidade do ser humano. Observa-se que o envelhecimento contemporâneo trouxe o surgimento de condutas, hábitos, crenças e imagens que influenciam diretamente na percepção que se tem da velhice, na identidade e até mesmo na memória. Se antigamente a imagem do envelhecimento estava ligado às perdas, à inatividade e ao descanso, na contemporaneidade surge um novo modelo identitário que inclui a manutenção das atividades, o estímulo à aprendizagem, a satisfação pessoal e a formação de vínculos inéditos na vida (Silva, 2008). Isso permite o engajamento do idoso que, no presente estudo, se fez presente principalmente com o ingresso do mesmo na universidade sênior trazendo novas perspectivas de vida para este idoso que já havia sofrido um dos principais desengajamentos sociais que ocorreu com a saída do trabalho devido à reforma.

Esse engajamento/desengajamento repercutiu na percepção do envelhecimento de forma muito relacionada às perdas físicas e cognitivas uma vez que interferiram nas escolhas de atividades que poderiam ou não realizar em suas rotinas, sem desconsiderar suas queixas de memória. A idade também surge como sendo um marcador do envelhecimento numa das falas dos idosos (Autor do Relato 3, 65 anos, sexo feminino) onde o mesmo relatou ter percebido estar envelhecendo aos 40 anos de idade e destaca as queixas cognitivas surgidas nesta época.

Destacando a idade como fator marcante do envelhecimento, também é possível obervar suas divisões sob diferentes perspectivas. A primeira delas se refere à idade biológica em que há associação ao funcionamento orgânico e onde a perda das capacidades essenciais registram-se influenciando no quadro geral de saúde. A segunda à idade psicológica, que trás consigo as capacidades de adaptação ao meio ambiente preservando os mecanismos de controle e de autoestima. Já a terceira, Idade Social que diz respeito aos papéis sociais, posição e participação social (Luz, 2014). Também convém destacar o Idadismo. O "idadismo" é um termo surgido pela primeira vez em 1969 pelo psicólogo americano Robert Butler para explicar reações negativas de uma determinada comunidade face a construção de 
imóveis para idosos na sua vizinhança. A idade dos idosos que iriam habitar aquela localidade foi o centro da preocupação dos demais residentes. O idadismo, contudo, se refere "às atitudes e práticas negativas generalizadas em relação aos indivíduos baseadas somente numa característica - a sua idade" (Marques, 2011, p.18).

Percebeu-se que a fala dos idosos trouxe também formas diferentes de identidade. Apesar de haver algumas semelhanças entre as atividades com as quais eles se identificam e realizam em sua rotina, notou-se que suas identidades seguem em constante transformação e mantém uma relação direta com suas memórias, não somente do ponto de vista das memórias de vida (trajetórias de vida), como também do ponto de vista cognitivo. A cognição poderia então ser sugerida como outro aspecto importante na construção, manutenção e aperfeiçoamento da identidade do idoso. Berlato (2009) destaca que a construção da identidade social de um determinado indivíduo é estabelecida a partir dos parâmetros definidos pelo meio social. Portanto, o que se percebe é que as perdas adquiridas ao longo da vida, conforme os próprios relatos dos idosos participantes deste estudo, são acompanhados por uma metamorfose identitária que também se relaciona com a idade.

No que se refere à percepção subjetiva de memória do idoso foi observado que houve uma predominância de queixas ligadas a constantes episódios de esquecimento que remeteu para o lado negativo. Mesmo assim não afirmamos aqui que essa percepção foi positiva ou negativa, mesmo diante da presença das queixas, mesmo porque seriam necessários mais relatos que nos permitissem tal afirmação. No estudo de Espírito-Santo, Pena, Garcia, Pires, Couto \& Daniel (2016) é possível observar a confirmação das queixas subjetivas de perda da memória como sendo frequente em idosos. No estudo de Lindôso, Cammarota, Argimon, Gomes \& Scwanke (2011), a percepção subjetiva de memória dos idosos foi predominantemente negativa. Os idosos estudados eram igualmente ativos e frequentavam uma oficina de inclusão digital numa universidade brasileira. Considerando as devidas diferenças culturais e de população/amostra dos estudos, percebemos que os idosos da universidade sênior têm conseguido manter-se nas atividades da mesma forma que os idosos do estudo dos autores citados. Convém aqui destacar a lembrança como parte do processamento da memória. Elas contribuem na construção da cultura e no estabelecimento do vínculo do que se passou com o que está por vir (Marinho, 2016). Portanto, esquecer (perder a lembrança) seria como ter a chance de perder este vínculo e de manter a construção da cultura no idoso. O esquecimento, por outro lado, sempre implicará ao idoso uma superação.

A superação das limitações demonstraram que mesmo os idosos tendo demonstrado conformismo para certas situações, as mesmas podem ser encaradas de 
formas diferentes para o seguimento do curso da vida. Isso permite o desenvolvimento das memórias do idoso. A literatura atual já mostra claramente que a importância dessa função cognitiva vai além das questões biológias. A memória também tem grande importância na vida social do indivíduo. A utilização do termo "memória coletiva", definida por Maurice Halbwachs, permite fazer uma relação entre a memória, a identidade e o envelhecimento. Se ao longo da vida colecionamos "memórias" elas serão constantemente acessadas quando houver necessidade de lembrá-las. Todas essas lembranças estão ligadas a acontecimentos sociais que foram determinantes no processo de armazenamento das informações, ou seja, no processamento da memória. Este conceito partiu justamente do ponto em que o autor coloca que nossas memórias não são somente nossas e o que o grupo social é um determinante nesse processo. Para Halbwachs, o indivíduo isolado da vida social não seria capaz de construir suas experiências (Silva, 2016).

Todos os apontamentos descritos anteriormente estão em consonância com as teorias sociais do envelhecimento e com as teorias da representação social. Do ponto de vista das teorias das representações sociais, percebemos que os idosos trouxeram em suas falas as complexidades, os sentimentos e escolhas que nos mostram que o avanço da idade representa também oportunidades, mesmo diante das perdas. Foi possível observar também que o idoso não se separa do ambiente, eles interagem constantemente e se tornam protagonistas de sua própria história de vida e que buscam adequações para todas as suas inquietações. É justamente este protagonismo que faz perceber a interação entre o idoso, o ambiente e a sociedade tão bem enfatizado pelas teorias das representações sociais.

Já com relação as teorias sociais do envelhecimento, observou-se que todas se fizeram presentes em momentos diferentes. No momento em que o idoso traz sua história de vida, as percepções sobre o envelhecimento e eles se entrelaçam com tudo que se já tem de conhecimento sobre o mesmo. Quando ele resolve encarar suas dificuldades para manter uma identidade social por meio de suas preferências, e até mesmo quando demonstra conformismo, podemos destacar a teoria da continuidade do envelhecimento. A teoria da subcultura também surge quando os idosos se posicionaram como uma categoria à parte das demais etapas da vida e até mesmo quando relatam a idade como fator marcador de seu envelhecimento. A teoria da gerotranscendência foi observada quando os idosos relataram (Autor do Relato 1, 71 anos, sexo feminino; Autor do Relato 2, mais de 80 anos, sexo masculino e Autor do Relato 4, 65 anos, sexo feminino) suas preferências pelo contato pessoal, quando fizeram novos laços de amizade ao ingressar na universidade sênior (engajamento social), e ainda quando a reforma surge como um desengajamento social e que interfere no poder aquisitivo. Entretanto, esse processo de desengajamento oportunizou a 
estes idosos tempo livre para o ingresso na universidade sênior. Esse contraponto entre o aspecto negativo e positivo nos remete a citar diretamente a teoria do desengajamento.

Acredita-se que a teoria da atividade foi a que mais se fez presente nos relatos dosidosos, pois todas as atividades em que se engajaram ou desengajaram em suas vidas trouxeram repercussões positivas e negativas. As negativas refletiram principalmente na percepção do envelhecimento e nas queixas de memória. Também refletiram nos sentimentos de humilhação e frustração relatados pelos idosos. As positivas focaram na manutenção da identidade social. Esta teoria também se fez presente no momento em que os idosos trouxeram suas estratégias de enfrentamento das dificuldades em relação às queixas de memória. O êxito das realizações proporcionam senso de ajustamento social para o idoso e o prepara para o enfrentamento de tarefas futuras (Eliopoulos, 2001; Neri, 2013; Stamato, 2007).

As teorias aqui elencadas permitem afirmar, portanto, que todos os pensamentos expostos pelos idosos durante os diálogos trazem consigo uma bagagem cognitiva e de identidade social, e isto novamente evidencia a existência dessa relação, pois a memória e a identidade são disputadas nas relações sociais e intergrupais (Pollak, 1992).

Os resultados encontrados neste estudo permitem afirmar que a história de vida de cada idoso participante trouxe influências em seus comportamentos, em tomadas de decisão e no próprio estilo de vida dos idosos, e como já descrito anteriormente, as transformações societárias vivenciadas por cada um permitiram a obtenção de suas percepções em relação às representações sociais da velhice e sobre seu processo de socialização. Nesse sentido, os processos cognitivos como a memória ganham uma importância maior por serem parte desse contexto de transformações. Os discursos dos idosos trouxeram semelhanças e diferenças. Isto não significa dizer que os resultados obtidos permitem afirmar que os idosos representam uma categoria uniforme, mesmo porque toda categoria etária trás consigo semelhanças e diferenças, o que difere é a forma como cada um lida com elas.

Os idosos participantes deste estudo partilham de um ambiente importante para suas vidas e que trouxe repercursões diferentes para si: a universidade sênior. Esse espaço representa um bom exemplo de que as transformações ocorridas ao longo dos anos fez com que estes idosos passassem a fazer parte de uma mesma realidade tendo em vista suas próprias decisões, porém, cada experiência é individual dentro de um contexto coletivo. Essa coletividade, aliada a individualidade do idoso, permite a interação social, a manutenção/adaptação da identidade e suas percepções de maneira geral. Semelhanças de discurso não servem, neste caso, para processos de uniformização de uma categoria etária, pelo contrário, ela 
reforça o que foi anteriormente mencionado no que se refere às diferenças e semelhanças na percepção do indivíduo e da intensidade com que se apresentam em seu discurso ou diante de um investigador. Os aspectos referentes à "modernização reflexiva", às teorias sociais do envelhecimento e à teoria das representações sociais também se fazem presentes pois nos pontos em comum existentes entre elas há a importância de o indivíduo ser parte de uma sociedade e interagir com ela abrangendo toda a multidimensionalidade que as envolve.

Partindo desses pontos em comum, podemos considerar que, os mesmos, juntamente com as tomadas de decisão, as representações sociais, as histórias de vida e o imaginário dos idosos são vistos aqui como elementos/domínios de ligação na existência da relação entre a percepção subjetiva de memória, identidade social e envelhecimento - esses elementos/domínios têm em comum sua influência direta na maneira como os idosos direcionaram sua vida ao longo dos anos). $\mathrm{O}$ impacto disso na qualidade de vida foi notada justamente na manutenção do vínculo social e suas abragências na vida do idoso.

Os idosos aqui estudados concebem sua qualidade de vida partindo de suas tomadas de decisão, permitindo-se às transformações da vida, vivenciando suas queixas/dificuldades e buscando alternativas para elas. Esse suporte social, obtido também na universidade sênior, coloca o idoso diante de novos desafios de vida e reforçam que o bem-estar (físico, cognitivo, psicológico e social) são de fato uma preocupação constante para esta população. O estudo de Silva (2017) cita que o envelhecimento e a qualidade de vida em pessoas idosas salientam-se como preocupações sociais. Convém citar que qualidade de vida não se refere a viver mais anos somente, mas, sobretudo, a possibilidade de viver melhor (Silva, 2017). Isso implica que a cada novo rumo a ser traçado na vida, o idoso jamais se distanciará de sua identidade, suas percepções (memória) e suas maneiras individuais de vivenciar seu envelhecimento.

O presente estudo passou por algumas limitações com destaque para o acesso institucional e período letivo. A principal consequência destas limitações foi a influência na amostra do estudo que foi reduzida. Mesmo assim, os resultados não foram desconsiderados e um novo caminho para análises futuras foi oportunizado, além do fato de os objetivos do estudo terem sido alcançados.

\section{Considerações finais}

O presente estudo trouxe um tema pouco explorado, e embora a literatura traga informações pertinentes, ainda há necessidade de se focar mais a memória no contexto social considerando a história de vida dos idosos. Acredita-se que a proposta do presente 
estudo representa uma importante contribuição nesse sentido. Apesar da ocorrência de algumas limitações, o estudo conseguiu alcançar o objetivo a que se propôs.

Os relatos trazidos pelos idosos, além de terem representado um momento único para eles, fizeram perceber que as influências das teorias das representações sociais e as teorias sociais do envelhecimento se mantêm no comportamento desses idosos. A percepção de velhice ainda é predominantimente negativa com poucos destaques positivos para esta etapa da vida, e, por ser inevitável, o envelhecimento para esses idosos trouxe consigo sentimentos de conformismo, humilhação, amor, desengajamento e engajamento sociais, e tudo isso os permitiu fazer suas escolhas diante da vida. Talvez, se houvesse um maior número de participantes poderia se ter maior parâmetro comparativo, embora seja de conhecimento que as visões negativas da velhice ainda habitam o imaginário dos indivíduos de maneira geral.

Outro ponto importante é que o funcionamento da memória foi visto como um grande influenciador do comportamento e ajustamento social do indivíduo. Pudemos observar nos conteúdos de cada relato que as queixas de memória se encontravam presentes em todos nas falas de todos os participantes, porém, cada um encontrou uma forma de lidar com elas. Logicamente que há uma tendência de sentimentos de frustração quando há a ocorrência dessas falhas e isso também esteve presente na fala dos idosos.

Todos permanecem no convívio social e com laços sociais estabelecidos respeitando seus interesses atuais e isso ressalta a importância de se ter espaços/equipamentos sociais como as universidades sênior para que os idosos possam manter-se em plena atividade e protagonizando suas próprias vidas.

Ficou claro também que a construção da identidade necessita da interação do indivíduo consigo mesmo e com o mundo. Nesse contexto há um intenso processamento de informações que demandam o adequado funcionamento da memória.

Adicionalmente, ficou claro que os resultados não apontam para um processo de uniformização etária, mas sim, permitiram perceber que suas percepções obedeceram suas histórias de vida. Isto significa que a relação entre o passado, o presente e perspectivcas futuras de cada idoso participante deste estudo irão depender das experiências vividas em diferentes épocas.

Os destaques anteriores nos permitem conceber um encontro entre a "modernização reflexiva", as teorias sociais do envelhecimento e a teoria das representações sociais, que formam uma importante aliança junto as tomadas de decisão, as representações sociais, as histórias de vida e o imaginário do idoso. Além disso, este nos permite entender ser este um importante elo de ligação para a existência da relação entre a percepção subjetiva de memória, identidade social e envelhecimento. A existência da referida relação tem influência direta na 
qualidade de vida dos idosos que têm nela a oportunidade de viver melhor sua velhice e seguir sendo protagonista de sua própria história.

Estudos adicionais deverão investigar com maior profundidade esta relação partindo dos resultados aqui obtidos e incluir um maior número de idosos para que se obtenha informações mais precisas acerca desta temática. Aliado aos estudos qualitativos baseados nas narrativas de vida, os estudos quantitativos poderão também ser desenvolvidos para se verificar a associação existente entre memória, identidade e envelhecimento do ponto de vista estatístico e com variáveis específicas. Estes poderiam ser transversais e/ ou longitudinais. Acredita-se que os resultados obtidos com a utilização dessas duas metodologias possam trazer novas formas de pensar e proporcionar resultados diferenciados que permitirão um aprofundamento das questões que envolvem esse tema.

\section{Nota}

1 O termo "senescência" corresponde ao envelhecimento natural (Lima \& Cammarota, 2012).

2 A primeira publicação de Halbwachs sobre a memória social se deu por meio do artigo intitulado "Sur la Psychologie de L'ouvrier Moderne D'après Bernstein" no ano de 1905 na revista Revue Socialiste. Entre os anos de 1921 e 1925 Halbwachs produziu o livro intitulado Les Cadres Sociaux de la Mémoire e em 1950 publicou o livro La Mémoire Collective.

Por decisão pessoal, a autora escreveu este texto segundo as normas do antigo acordo ortográfico.

\section{Referências}

Beck, U. (2000). A reinvenção da política. In U. Beck, A. Giddens, \& S. Lash (Eds.), Modernização reflexiva - Politica, tradição e estética na ordem social moderna. Oeiras, Portugal: Celta.

Berlatto, O. (2009). A construção da identidade social. Revista do Curso de Direito da FSG, $3(5), 141-151$.

Bourdieu, P. (2002). Esboço de uma teoria da prática - Precedido de três estudos sobre etnologia Cabila. Oeiras, Portugal: Celta.

Caria, T. H. L. (2003). Bourdieu e o conceito de prática na pesquisa em educação. Educação \& Realidade, 28(1), 31-47.

Cordeiro, V. D. (2015). Por uma sociologia da memória: Análise e interpretação da teoria da memória coletiva de Maurice Halbwachs (Dissertação de mestrado). Universidade de 
São Paulo, Faculdade de Filosofia, Letras e Ciências Humanas, São Paulo, Brasil. Daniel, F., Antunes, A., \& Amaral, I. (2015). Representações sociais da velhice. Análise Psicológica, 33(3), 291-301. DOI: 10.14417/ap.972

Deon, R. G., \& Goldim, J. R. (2016). Capacidade para tomada de decisão em idosos institucionalizados e não institucionalizados. Estudos Interdisciplinares sobre o Envelhecimento, 21(1), 123-133.

Doll, J., Gomes, A., Hollerweger, L., Pecoits, R. M., \& Almeida, S. T. (2007). Atividade, desengajamento, modernização: Teorias sociológicas clássicas sobre o envelhecimento. Estudos Interdisciplinares sobre o Envelhecimento, 12, 7-33.

Domingues, J. M. (1999). Sociologia da cultura, memória e criatividade social. Dados, 42(2). DOI: 10.1590/S0011-52581999000200004

Eliopoulos, C. (2001). Enfermagem gerontológica (5ª ed.). Porto Alegre, Brasil: Artmed.

Espírito-Santo, H., Pena, I. T., Garcia, I. Q., Pires, C. F., Couto, M., \& Daniel, F. (2016). Memória e envelhecimento: Qual o real impacto da idade?. Revista Portuguesa de Investigação Comportamental e Social, 2(2), 41-54.

Fechine, B. R. A., \& Trompieri, N. (2012). O processo de envelhecimento: As principais alterações que acontecem com o idoso com o passar dos anos. International Scientific Journal, 1(20), 106-132.

Hall, S. (2003). A identidade cultural da pós-modernidade $\left(10^{\mathrm{a}}\right.$ ed.). Rio de Janeiro, Brasil: DP\&A.

Inouye, K., Orlandi, F. S., Pavarini, S. C. L., \& Pedrazzani, E. S. (2017). Efeito da Universidade Aberta à Terceira Idade sobre a qualidade de vida do idoso. Educação e Pesquisa, 44, e142931. DOI: 10.1590/s1678-4634201708142931

Kral, V. A. (1962). Senescent forgetfulness: Benign and malignant. Can Med Assoc J., 86(6), pp. 257-260.

Lima, R. H., \& Cammarota, P. M. (2012). Atualizações em memória e envelhecimento. In C. H. A. Schwanke, G. A. Carli, I. Gomes, \& Z. C. L. L. Lindôso (Orgs.), Atualizações em geriatria e gerontologia IV: Aspectos demográficos, biopsicossociais e clínicos do envelhecimento (pp. 81-96). Porto Alegre, Brasil: EDIPUCRS.

Lindôso, Z. C. L., Cammarota, M. P., Argimon, I., Gomes, I., \& Scwanke, C. H. (2011). Percepção subjetiva de memória e habilidade manual em idosos de uma oficina de inclusão digital. Revista Brasileira de Geriatria e Gerontologia, 14(2), 303-317. DOI: 10.1590/S1809-98232011000200011

Luz, H. R. A. (2014). Sociologia do envelhecimento. In M. T. Veríssimo (Coord.), Geriatria fundamental - Saber e praticar (pp. 65-74). Lisboa, Portugal: Lidel.

Marinho, M. S. (2016). Narrativas sobre o envelhecer: Memórias e identidades de idosos longevos (Dissertação de mestrado). Universidade Estadual do Sudoeste da Bahia, Vitória da Conquista, Bahia, Brasil.

Marques, S. (2011). Discriminação da terceira idade. Lisboa, Portugal: FFMS e Relógio d'Água.

Moraes, R. P., Souza, I. C., Pinto, D. A. O., Estevam, S. J., \& Munhoz, W. A. (2014). A teoria das representações sociais. Direito em Foco, 17-30. Disponível em 
http://unifia.edu.br/revista_eletronica/revistas/direito_foco/artigos/ano2014/te oria_representacoes.pdf

Moscovici, S. (1961). Reconversion industrielli et changements sociaux, un exemple: La chapellerie dans l'Aude. Paris: A. Colin.

Mota, M. (2000). Uma introdução ao estudo cognitivo da memória a curto prazo: Da teoria dos múltiplos armazenadores à memória de trabalho. Estudos de Psicologia, 17(3), 15-21. DOI: 10.1590/S0103-166X2000000300002

Neri, A. N. (2013). Conceitos e teorias sobre o envelhecimento. In L. F. Malloy-Diniz, D. F. Fuentes, \& R. M. Cosenza (Eds.), Neuropsicologia do envelhecimento: Uma abordagem multidimensional (pp. 17-42). Porto Alegre, Brasil: Artmed.

Patriota, L. M. (2007). Teoria das representações sociais: Contribuições para a apreensão da realidade. Serviço Social em Revista, 10(1). Disponível em http://www.uel.br/revistas/ssrevista/c-v10n1.htm

Pollak, M. (1992). Memória e identidade social. Estudos Históricos, 5(10), 200-212.

Prado, S. D., \& Sayd, J. (2006). A gerontologia como campo do conhecimento científico: Conceito, interesses e projeto político. Ciência e Saúde Coletiva, 11(2), 491-501. DOI: 10.1590/S1413-81232006000200026

Santinello, J. (2011). A identidade do indivíduo e sua construção nas relações sociais: Pressupostos teóricos. Revista de Estudos da Comumunicação, 12(28), 153-159.

Silva, G. F. (2016). A memória coletiva. Aedos, 8 (18), 247-253.

Silva, L. R. F. (2008). Terceira idade: Nova identidade, reinvenção da velhice ou experiência geracional?. Physis. Revista de Saúde Coletiva, 18(4), 801-815. DOI: 10.1590/S0103-73312008000400011

Silva, M. J. D. (2017). O envelhecimento ativo: o apoio das tecnologias da informação e comunicação e das redes de suporte social. (Dissertação de Mestrado). Escola Superior de Educação de Paula Frassinetti, Porto.

Stamato, C. (2007). Modelo de banheiro domiciliar para idosos: Uma abordagem ergonômica (Dissertação de mestrado). Pontifícia Universidade Católica do Rio de Janeiro, Rio de Janeiro, Brasil.

Viegas, S. M., \& Gomes, C. A. (2007). A identidade na velhice. Lisboa, Portugal: Ambar.

Vieira, E. B. (2004). Manual de gerontologia: Um guia teórico-prático para profissionais, cuidadores e familiares. Rio de Janeiro, Brasil: Revinter.

Woodward, K. (2000). Identidade e diferença: Uma introdução teórica e conceitual. In T. T. Silva (Org.), Identidade e diferença: A perspectiva dos estudos culturais (pp. 7-69). Rio de Janeiro, Brasil: Vozes.

Data de submissão: 13/10/2017 | Data de aceitação: 04/01/2018 